\title{
Saúde como ausência de doença: crítica à teoria funcionalista de Christopher Boorse
}

\author{
Health as absence of disease: critique to \\ the functionalist theory of Christopher Boorse
}

Naomar de Almeida Filho 1

Vládia Jucá 1

\footnotetext{
1 Instituto de Saúde Coletiva, Universidade Federal da Bahia. Rua Padre Feijó, 29/4ㅇ andar. 40210-070 Campus Canela, Salvador BA. naomar@ufba.br
}

\begin{abstract}
This paper is an introduction to Cristopher Boorse's work. Boorse is a philosopher of medicine who created, in the 70s, the Bioestatistical Theory (BST). In this paper, we look into the structure of BST and its arguments, focusing on its epistemological basis as well as its logical and theoretical reasons for defining health as the absence of disease. After that, we discuss the critics addressed to Boorse throughout these twenty years of theorization by analyzing their actuality and adequacy. We also identify problems and strong points in the BST, bringing up not only the crit$i c s$ to the BST but Boorse's answers as well. Finally, we add some questions that can provide continuity and enrichment to the debate on the concept of health with the aim of exploring its applicability in a general health-disease-care approach, which is extremely necessary at this moment of articulation between biological and eco-social perspectives on healthdisease phenomena.
\end{abstract}

Key words Health concept, Concept of disease, Epistemology, Boorse, Functionalisty theory
Resumo Este ensaio é uma introdução à obra de Cristopher Boorse, filósofo da medicina que criou, nos anos 70, a Teoria Bioestatística da Saúde (TBS). Em primeiro lugar, examinamos o argumento e a estrutura da TBS, destacando seus elementos epistemológicos fundamentais e principalmente as justificativas lógicas e teóricas de sua definição da saúde como ausência de doença. Em segundo lugar, discutimos as numerosas criticas recebidas por Boorse em duas décadas de circulação dos seus textos, buscando estabelecer a pertinência e atualidade dessas críticas. Em seguida, identificamos problemas e pontos fortes da teoria boorseana, retomando as principais críticas dirigidas ao autor, bem como suas tentativas de resposta. Por fim, levantamos algumas questões que podem propiciar uma continuidade e um enriquecimento do debate em torno do conceito de saúde a fim de explorar sua aplicabilidade para uma teoria geral da saúde-doença-cuidado, cada vez mais necessária neste momento em que se pretende uma maior articulação entre abordagens biológicas e ecossociais dos fenômenos da saúde e da doença.

Palavras-chave Conceito de saúde, Conceito de doença, Epistemologia, Boorse, Teoria funcionalista 
O presente artigo tem como objetivo avaliar criticamente a obra de Cristopher Boorse, professor de filosofia da biologia e filosofia da medicina na Universidade de Delaware (EUA), onde vem se dedicando a desenvolver uma teoria naturalista da saúde. Em meados da década de 1970, esse autor escreveu uma série de artigos sobre problemas filosóficos e conceituais das noções de saúde e doença que veio a constituir a Teoria Bioestatística da Saúde (TBS) conforme designação proposta por Nordenfelt (1987). Desde sua publicação, o trabalho de Boorse tem recebido críticas ferozes e apoios apaixonados, provocando grande controvérsia entre filósofos e cientistas sociais interessados em saúde. Pela importância das questões levantadas e pelo seu caráter polêmico e corajoso, a proposta boorseana e suas atualizações (Boorse, 1975, 1976, 1977, 1987, 1997) sem dúvida constituem importante ponto de partida para uma reflexão sobre a complexidade da saúde humana. No Brasil, o nome de Boorse é praticamente desconhecido e não há referências a sua contribuição em qualquer dos textos analíticos fundamentais da área da saúde coletiva no país. Por esse motivo, esperamos com o presente trabalho também contribuir para o enriquecimento do debate nacional sobre tema tão relevante e oportuno.

Em primeiro lugar, examinaremos brevemente a estrutura da teoria da saúde-doença de Cristopher Boorse, destacando seus elementos epistemológicos fundamentais e principalmente as justificativas lógicas e teóricas de sua definição da saúde como ausência de doença. Em segundo lugar, merecem ser apresentadas e avaliadas as numerosas críticas recebidas por Boorse em duas décadas de circulação dos seus textos, buscando estabelecer a pertinência e atualidade dessas críticas. Em seguida, pretendemos identificar problemas e, principalmente, pontos fortes da teoria boorseana, a fim de explorar sua aplicabilidade para uma teoria geral da saúde-doença-cuidado, cada vez mais necessária neste momento em que se pretende uma maior articulação entre abordagens biológicas e ecossociais dos fenômenos da saúde e da doença.

\section{Uma teoria negativa da saúde-doença}

Explicitando seu marco epistemológico de referência, Boorse (1975) apresenta-se como um representante do naturalismo, em contraposição a enfoques que classifica como normativis- tas. O normativismo, na sua opinião, compreende duas vertentes: uma radical, que define os conceitos de saúde e doença como puros julgamentos (pure evaluation) de valor, e outra designada como normativismo fraco, que admite a existência de componentes normativos e descritivos nos julgamentos de saúde. De todo modo, o normativismo é refutado por Boorse com base no seguinte argumento: se fosse válida uma interpretação valorativa da saúde, não se poderia chamar de doença os fenômenos patológicos em plantas e animais. Nesse caso, a expressão "saúde animal", de uso corrente na medicina veterinária, não passaria de uma analogia instrumental. Em contraponto, o naturalismo à la Boorse, com fundamentação e ancoragem na biologia evolutiva, pretende assumir que os conceitos de saúde-doença podem ser essencialmente descritivos e, como tal, isentos de valor.

Compreendendo que uma conceituação valorativa de saúde implica o que se considera desejável para o indivíduo ou para a sociedade, Boorse defende a tese de que, se soubermos diferenciar doença de enfermidade, podemos encontrar uma noção de saúde destituída de quaisquer valores. Para explicar melhor este ponto, afirma o próprio autor:

A questão é que enfermidade é uma mera subclasse da doença, isto é, aquelas doenças que têm certas características normativas refletidas nas instituições da prática médica. Uma enfermidade deve ser, primeiro, uma doença razoavelmente séria com efeitos incapacitantes que a fazem indesejável (...) Segundo, chamar uma doença como enfermidade é considerar seu portador como merecedor de tratamento especial e com responsabilidade moral diminuida (...) Onde não se fazem julgamentos normativos apropriados ou não se ativam as instituições sociais, nenhum volume de doença nos conduzirá ao termo "enfermo" (Boorse, 1975).

Vejamos os passos do raciocínio proposto por Boorse:

- doença é um conceito teórico;

- enfermidade constitui uma subclasse (prática) do conceito;

- portanto, a saúde terá duas definições, ambas negativas:

a) oposto de doença (saúde teórica);

b) oposto de enfermidade (saúde prática).

Segundo Boorse (1975), o conceito teórico de doença [...] se aplica indiferentemente a organismos de todas as espécies, [por isso] tal conceito deve ser analisado em termos biológicos mais 
do que em termos éticos. Doença seria, por conseguinte, o termo de referência pelo qual a saúde poderia ser negativamente definida, como um conceito teórico totalmente livre de valores. A saúde teórica seria "estritamente análoga" à condição mecânica de um artefato ou sistema físico. Por outro lado, uma enfermidade implicaria julgamento valorativo na medida em que se caracterizaria como incapacitante, objeto de tratamento especial e justificativa para comportamentos em geral socialmente reprováveis, garantindo ao portador relativa isenção de responsabilidades. A saúde prática, oposto da enfermidade, herdaria o caráter normativo do seu conceito-espelho e, portanto, seria desprovida de qualquer interesse heurístico para uma teoria formal da saúde.

Para fundamentar a sua formulação básica de que "saúde = ausência de doença", Boorse procura definir com precisão as noções de função biológica e normalidade estatística. Em todo o texto desse primeiro ensaio de 1975, encontra-se com insistência a afirmação de que "doença" constitui um conceito teórico, porém não se verifica qualquer esforço de estabelecer a positividade de tal conceito, tanto por suas modalidades quanto por suas propriedades. Por outro lado, Boorse indica com clareza uma primeira definição positiva de saúde: estado de um organismo cujo modo de funcionamento conforma-se ao "desenho natural" daquele tipo de ser vivo: A saúde de um organismo consiste no desempenho da função natural de cada parte [do organismo] (Boorse, 1975).

Em 1977, Boorse publica um texto seminal, intitulado "Health as a theoretical concept", no qual avança e detalha seu modelo teórico. A partir de uma reiteração da fórmula "saúde como ausência de doença”, revisa sistematicamente abordagens prévias que tomavam os conceitos de saúde ou de doença como: a) valor; b) objeto de atenção médica; c) normalidade estatística; d) ausência de dor, sofrimento ou desconforto; e) ausência de incapacidade; f) adaptação; g) homeostase. Em seguida, revisa algumas distinções (disease vs. illness, doença vs. entidade mórbida, saúde intrínseca $v s$. saúde instrumental) para apresentar de modo mais estruturado sua teoria funcional da saúde.

Enfoques da saúde como um valor-em-si altamente desejável para o ser são criticados por Boorse (1977) com base no contra-argumento de que existem situações indesejáveis (como a fome) que não constituem doença. A abordagem da doença como objeto designado da prá- tica médica, por ele curiosamente considerada "um tipo de positivismo médico" (a sort of medical positivism), é refutada por dois motivos. Por um lado, a medicina trata muitas condições que não define como doença, como por exemplo as intervenções cirúrgicas com fins estéticos. Por outro lado, muitos problemas nãotratáveis são considerados doença. A definição de saúde como normalidade estatística, por ele considerada uma "persistente intuição", recebe a crítica de que condições incomuns ou anormais (cabelos ruivos, sangue tipo O Rh negativo) não impedem perfeita saúde.

Boorse (1977) reconhece que o bem-estar e a plena capacidade dos sadios contrastam com a incapacidade, a dor e o sofrimento dos doentes. Entretanto, assinala que a detecção de lesões e processos patológicos sem sinais e sintomas, bem como a ocorrência de dor e desconforto em processos não patológicos como parto, menstruação e dentição, limitam a validade do conceito de doença como quadro clínico. Por outro lado, algumas doenças não provocam qualquer tipo de incapacidade e certas incapacidades são fisiologicamente típicas de etapas do ciclo vital normal ("babies don't walk" registra). Avaliando algumas abordagens que articulam o conceito de saúde com as noções biológicas de seleção, adaptação e meio-ambiente, Boorse as considera igualmente limitadas dado que existem variações adaptativas capazes de produzir patogênese. Finalmente, teorias da saúde baseadas no conceito fisiológico de homeostase são refutadas com base em contra-exemplos de doenças (surdez, paralisia, esterilidade) que não constituem quebra de equilíbrio.

Boorse considera sua abordagem uma teoria teleológica, na qual as funções biológicas são tidas como contribuições para a consecução de determinados objetivos - basicamente, a sobrevivência e a reprodução (Boorse, 1976). Para se manter vivo, um organismo requer, obviamente, todo um complexo de funções em ação. A queda na eficiência de uma dessas funções biológicas, completa ou parcialmente, seria determinante de processos patológicos. $\mathrm{E}$ como definir o que é esperado de uma função? Nesse momento, Boorse recorre à estatística, a partir da qual seria possível estabelecer critérios do funcionamento esperado para uma determinada classe, compreendida como um grupo natural de organismos com um desenho funcional uniforme, geralmente um grupo delimitado pela espécie e pelo sexo. 
Uma função consiste em uma contribuição para uma meta. Organismos orientam-se teleologicamente e são capazes de se ajustar a mudanças ambientais para alcançar uma meta "programada". Boorse restringe o escopo da sua análise: diferentes subcampos da biologia reconhecem distintas metas e funções, mas somente o subcampo da fisiologia, cujas funções de interesse são sobrevivência individual e reprodução, tem relevância para a saúde.

A perspectiva funcionalista de Boorse funda-se sobre os conceitos de classe de referência e desenho da espécie: proposições de função referem-se a características da espécie ou população, nunca a indivíduos. Daí sua concepção chamar-se também estatística: espécies ou populações admitem média estatística para conformar seus tipos-ideais. Boorse (1977) propõe o conceito de desenho da espécie: uniformidade da organização funcional ou "hierarquia típica de sistemas funcionais entrelaçados que apóiam a vida de organismos daquele tipo". Adverte que a categoria não é inconsistente com a biologia evolucionista e, para justificar o conceito de classes de referência, considera ainda diferenças de sexo e idade intra-específicas.

Boorse (1977) define "funcionamento normal" por referência ao termo "eficiência", novamente tomando o âmbito da população como base para sua definição de "normalidade estatística". Aplica esse construto tanto a doenças que se manifestam como enfermidade quanto para aquelas condições latentes ou assintomáticas. De modo a poder usar o conceito de função para definir saúde, Boorse propõe a noção de "prontidão funcional" como alternativa ao conceito de funcionamento normal capaz de tornar o processo de funcionamento em estado ou condição de normalidade (funcional). Boorse realiza a crítica de algumas anomalias a partir da TBS: a) doenças estruturais - dextrocardia, deformidades menores, etc. (que não poderiam ser identificadas como doença porque não representam "problemas de saúde"); b) doenças universais - cárie, aterosclerose, etc. (também não deveriam ser assim classificadas porque atendem ao critério bioestatístico de saúde). Finalmente, de modo absolutamente intrigante ou paradoxal, Boorse (1977) termina por definir doença como ausência de saúde.

Ainda nesse texto, Boorse (1977) produz comentários quase irônicos sobre conceitos positivos de saúde. Corretamente associa-os às propostas da medicina preventiva e medicina comunitária e, mais corretamente ainda, descobre que isso ocorre mais no plano retórico e no plano das práticas, porque nessas tendências ou movimentos o que se busca prevenir é a doença. Analisa três concepções de saúde positiva, usando o exemplo da capacidade atlética: 1) potencial individual (individual potential);2) potencial da espécie (species potential); 3) saúde radical (unlimited view of health). Entre essas três positividades e a sua concepção negativa de saúde, reconhece as seguintes "disanalogias":

a) tomar saúde como excelência funcional conforma uma "utopia da saúde";

b) não há uma única direção para a saúde perfeita (saúde perfeita não é um ideal, mas admite vários);

c) ideais de saúde positiva não são descritíveis, somente defensáveis.

Em sua ofensiva contra a positividade do conceito de saúde, Boorse critica ainda propostas de equivalência entre saúde e "boa-vida" (no sentido do ideal platônico) como ingênuas, expressão de "vã esperança" de atribuir objetividade científica a valores pessoais e morais. No que se refere às bases lógicas de conceitos de saúde como excelência física, mental ou moral, Boorse (1977) identifica um problema de consistência: trata-se de uma tendência a condensar em um único termo uma noção de valor neutro, liberdade de doença, e a mais controversa de todas as prescrições - a receita para um ser humano ideal.

Dez anos depois, em um capítulo intitulado Concepts of Health, Boorse (1987) reitera sua intenção de "oferecer uma análise isenta de valores" como base para um conceito teórico de saúde, no mesmo registro dos conceitos biológicos de vida-morte. Entre nós, a obra pioneira de Mário Chaves (1972) já apresentava uma concepção negativa de saúde como capacidade de funcionamento do organismo em um ecossistema resultante da oposição ErosTânatos, em um registro intrigantemente similar à proposição tardia de Boorse.

Como eixo de estruturação de uma teoria da saúde, Boorse (1987) propõe usar o termo "normal” no lugar de "saúde", e patológico em substituição a "doença". Isto porque doença constituiria um termo tendencialmente ambíguo ou confuso, dada a sua extrema abrangência. O "patológico" seria mais preciso por sua correlação com as idéias de função biológica e normalidade estatística. Assim, reafirma uma relação linear de implicação entre quatro conceitos básicos: "classe de referência”, "função 
normal", "patologia", "saúde”. A classe de referência consiste no universo de membros de uma espécie biológica, do mesmo sexo e faixa etária. A função normal se define pela contribuição individual, "estatisticamente típica" em relação à classe de referência, para a sobrevivência e reprodução da espécie. Patologia: redução da "eficiência típica" implicada na função normal. Saúde significa simplesmente ausência de patologia. Com base em uma concepção do normal definido estatística e funcionalmente, o patológico pode ser concebido como seu contraponto:

A condição de uma dada parte ou processo em um organismo é patológica quando a capacidade dessa parte ou processo para executar uma ou mais de suas funções biológicas espécie-típicas cai abaixo de uma faixa central de distribuição estatística para aquela capacidade em partes ou processos correspondentes nos membros de uma classe de referência apropriada da espécie (Boorse, 1987).

Sendo o conceito de "condição patológica" formulado nesses termos, aparentemente justifica-se no plano lógico uma definição de saúde como ausência de doença. Assim, Boorse completa sua "teoria bio-estatística de saúde" com uma tautologia proposital indicando que, além da inexistência de patologia, o conceito de saúde poderá implicar simplesmente normalidade, "sempre no sentido de ausência de condições patológicas". Essa perspectiva assegura, em última instância, uma distinção "entre saúde teórica, ausência de doença e saúde prática, esta última de certo modo significando a ausência de enfermidade tratável", conforme estabelecido desde "Health as a theoretical concept" (Boorse, 1977).

Não faz muito tempo, Boorse (1987) autocriticamente admitiu a necessidade de superar uma concepção negativo-evolutiva (com base no gradiente disfunção-patologia-enfermidade) da saúde, propondo em seu lugar uma noção de "graus de saúde". Isto implica uma definição extremamente restrita de saúde positiva como grau máximo de saúde possível, em contraponto a qualquer redução da função normal ótima para a classe de referência. Normalidade, nessa concepção, teria três níveis de especificação: normal teórico, normal diagnóstico e normal terapêutico. O oposto lógico do conceito de patologia seria a normalidade teórica (ou conceitual). Para os outros níveis de normalidade, caberiam os respectivos antagonistas: anormal diagnóstico e anormal terapêutico. Fi- nalmente, Boorse considera as situações extremas de illness (contraposta a wellness) e de morte-vida. As relações de pertinência e de oposição estruturantes desse interessante esquema encontram-se representadas na figura 1.

Vinte anos após a publicação de seus primeiros trabalhos, revendo suas reflexões a fim de produzir uma réplica a seus críticos, Boorse (1997) apresenta um conceito de saúde que nos parece eficaz no sentido de congregar as noções apresentadas esparsamente em suas publicações:

Saúde teórica é a ausência de doença (...) então a classificação de estados humanos como saudáveis ou doentes é uma questão objetiva, a ser extraída dos fatos biológicos da natureza sem necessidade de juízos de valor. Designemos esta posição geral como naturalismo - o oposto do normativismo, a visão de que juízos de saúde são ou incluem julgamentos de valor (Boorse, 1997).

Neste trecho, encontramos resumidos os elementos essenciais da BST, que seriam:

a) saúde como objeto teórico;

b) naturalismo ou a objetividade na distinção saúde e doença;

c) conceito de doença relacionado ao cumprimento deficiente de uma função biológica que se encontra comprometida porque um dos componentes dessa função acha-se fora da normalidade estatisticamente definida;

d) saúde como ausência de doença.

Ao revisar sua teoria, Boorse (1997) afirma não mais acreditar que a diferença entre as categorias de doença e enfermidade possa ser lida como uma diferença de severidade (o que anteriormente ficava implícito). Por conseqüên-

Figura 1

Modelo dos graus de saúde de Boorse.

\begin{tabular}{|c|c|c|c|}
\hline \multicolumn{3}{|c|}{ Saúde subótima } & Saúde positiva \\
\hline \multicolumn{3}{|c|}{ Patologia } & Normalidade teórica \\
\hline \multicolumn{3}{|c|}{ Anormalidade diagnosticada } & $\begin{array}{l}\text { Normalidade } \\
\text { diagnosticada }\end{array}$ \\
\hline \multicolumn{2}{|c|}{$\begin{array}{l}\text { Anormalidade } \\
\text { terapêutica }\end{array}$} & \multicolumn{2}{|c|}{ Normalidade terapêutica } \\
\hline \multirow{2}{*}{ Morte } & Doença & \multicolumn{2}{|c|}{ Bem-estar } \\
\hline & \multicolumn{3}{|c|}{ Vida } \\
\hline
\end{tabular}


cia, reconhece então a possibilidade de considerar igualmente isentas de valores tanto a doença quanto a enfermidade. Trata-se de uma mudança de posição significativa que não nos parece suficientemente esclarecida. A idéia de "doença" deixaria então de ter um sentido diferenciado de "enfermidade"? Tem-se a sensação de que o salto operado pelo autor repousa mais no desejo de sustentar a TBS como uma teoria da saúde livre do normativismo, do que em justificativas mais plausíveis.

A definição de saúde elaborada por Boorse chama atenção pela sua insistente negatividade. Em toda a sua obra, uma definição positiva de saúde é propositadamente evitada, apesar de o autor reconhecer a existência, na atualidade, de um movimento forte no sentido da prevenção e promoção da saúde e da qualidade de vida, inclusive em níveis mais coletivos. Boorse justifica seu afastamento de uma concepção positiva de saúde pelo fato de que tal abordagem apresentaria sérias incompatibilidades com a TBS. Em primeiro lugar, estaria a dificuldade em determinar um ponto no sentido do qual a saúde deveria ser promovida: ... não só não há qualquer meta fixa de perfeita saúde para se alcançar, mas também não há uma única direção para se avançar (Boorse 1977). Em segundo lugar, qualquer concepção positiva substantivaria a saúde e, mais ainda, a elevaria ao plano do ideal.

\section{Críticas à teoria de Boorse}

A saúde como ausência de doença - proposição que Boorse considera central na TBS - é criticada por vários autores. Para Ladd (1982), a saúde precisa ser considerada de modo positivo e, mais ainda, que tanto a saúde como a doença seriam incomensuráveis. Entre seus argumentos, recorre à etimologia histórica para criticar as posições defendidas por Boorse, lembrando inicialmente que, entre os gregos, havia deuses distintos para a saúde e para a doença e, em acréscimo, que saúde e doença não têm nenhuma relação etimológica. Na perspectiva de Boorse, para quem a etimologia e a teologia seriam instrumentos fracos para a justificação de conceitos científicos, esses argumentos não seriam válidos. Sobre uma teoria positiva de saúde, Boorse (1997) acrescenta que se poderia pensá-la como uma função fisiologicamente superior ou como uma capacidade funcional, saídas conhecidas por Ladd, que pareceram não satisfazê-lo. É difícil afirmar que tal solução te- ria sido suficiente para o próprio Boorse, que, ao mesmo tempo em que as apresentava desde seus primeiros textos, já apontava alguns de seus limites.

As funções passadas e presentes (em uma perspectiva biológica de evolução) constituem outro espaço de questionamento para críticos de Boorse. Surpreendente, segundo o próprio autor, é que seus críticos nesse aspecto partem de um mesmo ponto, mas elaboram críticas opostas. Engelhardt (1976) lembra que espécies atípicas hoje são mais bem adaptadas do que espécies comuns que guardam funções inúteis. Por outro lado, Wakefield (1992) argumenta que os mecanismos de um organismo teriam sido evolutivamente selecionados porque, em um dado ambiente, aumentavam a longevidade e a fertilidade, o que não quer dizer que haja necessariamente um mau funcionamento desses mecanismos em função do decréscimo das taxas de longevidade e fertilidade. Entre os dois autores, Boorse (1997) diz que se encontra mais próximo de Wakefield. Pensando na era contemporânea, seria visível o fato de que os homens sofreriam fisiologicamente e, mais ainda, psicologicamente, porque ainda funcionariam, sob muitos aspectos, de modo mais adaptado a uma sociedade gregária. O que não implica dizer, em concordância com Wakefield, que tais traços constituiriam uma patologia, mas sim, que eles ainda comporiam o "desenho típico da espécie humana".

As implicações clínicas da TBS, que dizem respeito tanto à saúde física quanto mental, são discutidas por Wulf, Pedersen \& Rosemberg (1986). Para esses autores, Boorse se equivocara ao desconsiderar o fato de que a doença não diz respeito a meros organismos biológicos, mas afeta seres humanos. Na TBS, portanto, a subjetividade não é considerada um elemento importante no entendimento dos processos saúde-doença. Boorse (1997) responde afirmando que não poderia concordar com a assertiva de que são seres humanos e não organismos biológicos que estão enfermos, dado que seres humanos são organismos biológicos, isto é, eles não são nada mais do que uma das espécies da terra.

Para Hare (1986), o pai da TBS teria sido vago em suas afirmações, especificamente ao empregar termos que ocupam uma posiçãochave no corpo da teoria, tais como: "interno", "estado", “espécies”, “típico", “causa ambiental” e "característica da idade do organismo". Respondendo à crítica de Hare, Boorse (1997) afir- 
ma que é impossível eliminar totalmente a imprecisão dos conceitos. Em função de casos borderline, os conceitos trariam consigo sempre um certo grau de borrosidade (fuzziness). $\mathrm{O}$ autor destaca ainda que o "padrão conceitual" por ele adotado é o da medicina, especialmente no que diz respeito ao termo "patológico". A discussão de Boorse sobre o tema da imprecisão o leva, em última instância, a uma reflexão sobre a adequação dos conceitos à realidade e, nesse sentido, o autor revela uma ambigüidade interessante: ao mesmo tempo em que acredita firmemente no poder descritivo dos conceitos, admite que a linguagem científica com a qual se tenta catalogar a realidade não pode cobrir a mesma em sua totalidade, pluralidade e complexidade.

Alguns autores acreditam que a pretensão de Boorse de desenvolver uma teoria naturalista da saúde teria resultado, ao contrário, na geração de um corpo teórico cuja normatividade permanecera presente, porém encoberta. As críticas que seguem essa vertente sustentam que a TBS não ficou isenta de análises valorativas, pelo menos, por dois motivos: o uso de termos específicos e a eleição de objetivos.

Sobre o uso dos termos, Fulford lembra que, em obras anteriores, Boorse define doença inicialmente como "desvio" da organização funcional das espécies e que, logo depois, emprega o termo "deficiência”. Para Fulford (1994), se o primeiro termo ainda pode ser visto como descritivo, o segundo certamente apresenta um caráter normativo. Uma série de outros termos é ainda destacada dos vários textos de Boorse, como sendo visivelmente valorativa. "Ambiente hostil", comportamento biologicamente "incompetente" e preconceitos "absurdos" são alguns desses termos.

Boorse reconhece ter empregado, em alguns momentos, uma retórica mais forte, porém argumenta que isso não implica ter utilizado termos normativos. Mais ainda, insiste ter elaborado uma abordagem naturalista da saúde, a partir da qual não se poderia, de modo algum, descrever valores:

O naturalismo na saúde poderia ser um tipo de descritivismo, na perspectiva de Fulford, apenas se a saúde fosse um conceito valorativo, o que exatamente eu nego. Eu sempre adotei "normativo" e "descritivo" como contrários, acreditando que nenhum valor pode ser descritivamente definido (Boorse, 1997).

Engelhardt (1984) e Brown (1985) sustentam que Boorse apresenta como objetivo maior do saber médico a sobrevivência das espécies. Boorse (1997) argumenta que seu trabalho se configura como uma reconstrução dos conceitos de saúde e doença a partir de classificações médicas. Para compreendê-lo, será certamente imprescindível considerar em quais classificações médicas se pauta a TBS. Trata-se das classificações oriundas da medicina teórica, pressuposto reafirmado constantemente por Boorse. Por esse motivo, a crítica de Engelhardt deve ser contestada por considerar as categorias de "problema médico" e "problema clínico" como se fossem sinônimas. Para Boorse, trata-se de dimensões distintas na medida em que o que define o problema médico é o que concerne ao patologista. A TBS estaria, portanto, isenta de normativismo nessa opção pela patologia, sendo sua categorização como tal um equívoco por parte dos que não compreenderam de que medicina tratava Boorse.

Boorse (1997) argumenta que seus críticos teriam dado a entender que a variabilidade humana seria extensa a ponto de tornar inviável definir o "desenho da espécie". Contra esse desdobramento, Boorse defende a existência de regularidades e reitera o que afirmara em "Health as a theoretical concept": Nossas espécies e outras são, de fato, altamente uniformizadas em estrutura e função; de outro modo não haveria validade no detalhamento extremo dos livros de fisiologia humana... (Borse, 1997). Seguindo esta linha de raciocínio, a TBS estaria ainda de acordo com a biologia contemporânea que considera as espécies uma realidade que pode ser descrita a partir de algumas características elementares. O que, por outro lado, não impediria que ocorressem "variações estatisticamente normais" entre indivíduos e nos níveis intraindividuais.

Não obstante a réplica de Boorse (1997), essa linha de crítica não parece estar ainda completamente esgotada. Nessa polêmica, um dos seus principais interlocutores é Tristram Engelhardt $(1976,1984)$, que critica a TBS por seu normativismo velado, expresso por meio da valorização da sobrevivência das espécies e, por outro lado, é criticado pelo estudo onde trata do discurso médico acerca da masturbação no século 19, na qual chegara à conclusão de que escolhas valorativas foram realizadas e de que a patologização da masturbação deu respaldo científico a sua condenação moral. Boorse (1997) pretende refutar a crítica de Engelhardt dizendo que: ... Eu respondi que a TBS nada afirmou sobre a sobrevivência das espécies 
(...) e também que a TBS não escolheu este ou qualquer outro valor.

Em defesa da proposta naturalista, Boorse aproveita para distinguir tanto a norma da descrição quanto a medicina teórica do campo da moral. Compreendemos a preocupação de Boorse em traçar tais distinções, justificadas pelos debates filosóficos em que a ciência, a ética, a moral são separadas para fins analíticos. Isso ocorre também com a separação entre conceitos normativos e descritivos. O problema com a radicalização dessas distinções é que a ciência (e a ciência médica, ou medicina "teórica”, que nos interessa aqui particularmente) não deixa de ser uma prática social, efetivada por sujeitos humanos. Os sujeitos da ciência não são exclusivamente cientistas, ou somente éticos, ou rigorosamente morais, mas congregam todas essas dimensões ao realizar seu métier. Além do mais, a pressuposição de que a TBS é descritiva e eficaz em traduzir o real, que respaldaria sua pretensão de imparcialidade e isenção de valores, revela-se problemática por todos os motivos apresentados pelos críticos de Boorse.

Para Whitbeck (1978), Brown (1985) e Reznek (1987), o conceito boorseano de doença teria adquirido um sentido demasiadamente amplo. Boorse (1997) admite abrir mão do conceito de doença, desde que a dimensão "patológica" aí permanecesse. Isso porque o contraponto normal-patológico suscitaria menos confusões do que a polaridade saúde-doença. Reitera que seu objetivo era destacar o conceito médico de saúde e que a saúde é descrita pela medicina teórica como "ausência de doença". No nível teórico, a partir do qual o patologista atua, pouco importaria o que pensa o sujeito doente. Portanto, trata-se realmente de doença e não de enfermidade, devendo-se ressaltar que a doença em questão é definida teoricamente a partir dos parâmetros da patologia. Em nossa avaliação, esse argumento, no seu conjunto, constitui um grande equívoco. Primeiro, Boorse supõe que a medicina opera algum conceito de saúde, mesmo negativo. A nosso ver, isso seria incompatível com o objeto de intervenção da prática clínica. Segundo, não se explica o fato de Boorse, mesmo identificando lacunas epistemológicas e teóricas no conceito biomédico de saúde, ainda assim contar com tal abordagem para fundamentar sua TBS.

Boorse (1997) finaliza sua réplica, esperando ter demonstrado que a TBS oferece o melhor quadro analítico disponível para as ques- tões propostas. A seguir, nos veremos na incumbência de frustrar a expectativa de Boorse, porque algumas críticas persistem, devendo ser reapresentadas a partir de novos argumentos. Além disso, outras questões e outros problemas identificados na construção da TBS, porém ainda não formulados com clareza, podem e merecem ser considerados.

\section{Paradoxos e aporias na teoria boorseana}

O conceito de saúde teórica de Boorse parece referir-se a uma saúde absoluta, incondicional. Restringe seu enfoque ao nível individual, refere-se ao nível sistêmico subindividual apenas como subsídio à teoria da função e trata brevemente do tema da saúde da espécie como condicionante da evolução biológica. Além disso, a insistência de Boorse em postular a "medicina teórica" como base da TBS parece contraditória com uma postura "naturalista" autêntica. Na perspectiva médica clássica, o naturalismo encontra-se intimamente vinculado à atividade clínica (Good \& Good, 1980). O olhar e o toque clínico, ao agir sobre a realidade corpórea, decifrariam os processos patológicos, traçando uma diferenciação entre estados de doença e estados saudáveis. Sempre no referencial do naturalismo, recentemente cresce o movimento denominado "medicina baseada em evidências", que desloca a fonte de referência da eficácia da biomedicina da experiência clínica para a demonstração experimental (Sackett et al., 1997).

No geral da ciência e no particular da biomedicina, defensores típicos do naturalismo tenderiam a se filiar a uma tradição empirista e não aceitariam de bom grado o primado da teoria. Ao se autodesignar como naturalista, Boorse cria a expectativa de que a clínica médica seria o local privilegiado de construção de conceitos médicos como doença e enfermidade. Entretanto, rejeita a experiência clínica como referência viável para a TBS e reafirma com veemência que somente a biologia e a patologia podem ser admitidas como base teórica da saúde-doença.

Este aparente paradoxo nos intriga e convida à reflexão, provocando algumas questões: por que um auto-assumido naturalista tomaria uma teoria como ponto de partida de sua argumentação? Por que um naturalista rejeitaria uma noção ontológica (por conseguinte natu- 
ralista), insistindo tanto em elaborar um conceito teórico de doença? Talvez Boorse, fiel à sua extração original de filósofo neokantiano, tenha buscado a suposta solidez de uma teoria científica como suporte conceitual da TBS. Mais do que o foco no cotidiano e na vivência subjetiva da enfermidade, referências a uma teoria biomédica parecem propiciar um certo grau de "realismo epistemológico".

De todo modo, acreditamos que este terá sido seu maior equívoco, determinando uma série de movimentos forçados na construção de uma argumentação rigorosa, porém fundada em pressupostos, pelo menos, questionáveis. A hipótese de que o conceito de doença porta componentes não-físicos, não-químicos e nãobiológicos tem sido um dos principais temas da antropologia médica contemporânea. Susser (1973), Kleinman, Eisenberg \& Good (1978) e Young (1982) justificaram satisfatoriamente a proposição de que os conceitos de disease, illness e sickness são distintos e devem referir-se a facetas diversas do complexo saúde-doençacuidado. Em sua obra, Boorse não faz qualquer referência a essa vertente analítica da teoria da doença, já estabelecida e difundida mesmo no período inicial da sua investigação filosófica. Por isso mesmo, permanece a questão de por que teria incorporado tão acriticamente o conceito biomédico de doença.

Uma possibilidade diz respeito à posição do próprio Boorse de que sua proposta se configura como uma teoria negativa da saúde, na qual a saúde poderia ser definida como "ausência de doença”. Considerando a articulação teórica de tais noções, surge uma dúvida: na TBS, a saúde é que se encontra negativamente definida ou, na realidade, a doença é que seria assim apresentada? Conforme vimos acima, ao contrário do que insiste em postular, Boorse nunca aborda descritivamente o que é doença, posto que rejeita a abordagem semiológica da clínica. Então se vê forçado a definir saúde nos termos funcionais (ou "bioestatísticos") da fisiologia, como doença é vista paradoxalmente como ausência de saúde. Para reforçar a idéia de função normal, Boorse termina propondo a noção de "disteleologia", incorporando os aspectos evolutivos (desvantagens ou handicaps) ativados por doenças ou falhas de órgãos para a seleção das espécies. Observamos aqui uma importante lacuna em sua análise: trata-se da omissão da dimensão da cultura (que inclui a própria medicina e seus aparatos) como protetora e criadora de próteses que compensam as “desvantagens evolutivas" e potencializam o "funcionamento normal".

Emerge do contraponto lógico desse argumento a formulação de que a doença pode ser definida como não cumprimento (total ou parcial) de uma função biológica, comprometida porque um de seus componentes encontra-se fora de uma normalidade "bioestatisticamente" definida. Afinal, na teoria biológica de função (e em seus desdobramentos) a saúde pode ser entendida como eficiência funcional, como doença ou patologia se definem por falha, defeito, desvio ou déficit de função, sendo, portanto, rigorosamente, ausência de normalidade.

O jogo lógico ["saúde = ausência de doença” $\Leftrightarrow$ "doença = ausência de saúde"] poderia ser interpretado como mera tautologia, mais uma das circularidades boorseanas. Entretanto, temos que considerar a possibilidade de que essa questão conforma uma "aporia", em pelo menos um dos sentidos filosóficos do termo (Lalande, 1995). Por um lado, no sentido aristotélico clássico, aporia implica a formulação de respostas contraditórias, porém igualmente racionais, a uma mesma questão. Por outro lado, no sentido moderno, aporia indica um impasse no plano racional, dificuldade lógica da qual não se pode escapar sem transgredir os fundamentos do pensamento. Em termos da TBS, aparentemente se impõe a segunda conotação, posto que a partir de seus desdobramentos, apresenta-se uma dificuldade lógica que, a menos que se alterem as próprias definições de saúde e doença, revela-se insolúvel.

Uma resposta possível para as críticas e paradoxos identificados neste texto seria que Boorse aparentemente não tem consciência de quão dialética é sua teoria. A insistência contraditória de um "naturalista” que postula uma "medicina teórica", a inexplicável rejeição de noções ontológicas de doença apesar de uma referência profunda à biologia evolutiva humana, o frustrado esforço de distinguir entre saúde e doença pela negatividade da saúde a partir de uma assimetria teórica, revelam indícios de inconsistências de uma teoria inadequada apesar de ambiciosa. Face ao acúmulo de anomalias, vemos certo potencial em interpretar a TBS como uma aporia aplicada, em vez de uma "dialética invertida/inadvertida". Desse modo, implícito na TBS estaria a postulação de que, resguardando uma clara incomensurabilidade, os conceitos de saúde e doença são interpenetráveis e não podem ser operados em isolamento. 


\section{Comentários finais}

Neste ensaio, buscamos superar dualismos tipo naturalismo $v s$. normativismo, ao mesmo tempo evitando as posições culturalista e subjetivista em suas vertentes mais radicais. Essa posição permite também questionar o realismo de cunho essencialista, ao qual Boorse parece se filiar ao acreditar num real que não está em nenhum mundo das idéias, mas que se encontra inscrito no corpo. Uma alternativa à saída encontrada por Boorse pode ser considerar que existe, no fato e no discurso, um real concreto que se coloca para os humanos, mas que só pode ser pensado e problematizado por meio da linguagem.

Assim, arriscamos afirmar, em cauteloso acordo com Byron Good (1994) e Arthur Kleinman (1986), que as medicinas compõem redes semânticas. A medicina clínica consistiria em uma prática ideológica e a medicina teórica se apresentaria mais como uma linguagem e um sistema cultural, com seus respectivos códigos particulares e relações valorativas. O conceito de rede semântica se refere à disposição associada de noções médicas, as quais compõem domínios que "refletem e provocam formas de experiências e relações sociais" (Good 1994). Chave do projeto de uma semiologia regional do campo da saúde, a abordagem das redes semânticas se impõe com certa urgência a partir de duas finalidades fundamentais.

Em primeiro lugar, para facilitar nossa exposição do mundo e nossa ação sobre o mesmo, utilizamos "conceitos" que significam mais que conteúdos ideativos, ainda que deficientemente problematizados (ou em estado prático, para usar uma terminologia althusseriana). As condutas dos profissionais de saúde são orientadas a partir de percepções silenciosas, sempre reveladas em atos. Dizem respeito, na realidade, a uma experiência diária, culturalmente constituída, na qual os profissionais se encontram imersos, e que se manifesta sob a forma de posições e decisões assumidas desde o âmbito clínico até o espaço mais amplo de formulação de políticas de saúde. No que concerne aos processos de vida, saúde, doença, sofrimento, morte, não se pode, como pretendeu Boorse, recalcar a clínica ou colocar a política entre parênteses.

Além do mais, em segundo lugar, numa época em que a "transdisciplinaridade" está na moda, torna-se crucial compreender como tais noções e conceitos são significados nos vários grupos profissionais e, particularmente, nas comunidades científicas para melhor refletir sobre as reais possibilidades de efetivação das propostas "trans" qualquer coisa. Uma proposta a ser descartada consiste na difusão ou circulação dos discursos produzidos pelos distintos campos disciplinares, tarefa impossível pela via da comunicação, dada a incomensurabilidade dos campos e paradigmas científicos. Por outro lado, uma alternativa a ser considerada implica uma definição pragmática da transdisciplinaridade como processo, estratégia de ação, modalidade de prática, e não como propriedade ou atributo de relações modelares entre campos disciplinares (Almeida Filho, 2000a). Não se pode, como também pretendeu Boorse ao tomar a biologia como fundamento privilegiado da TBS, postular uma hegemonia "natural" de um dado discurso científico em um campo disciplinar e sobre um objeto complexo como o complexo saúde-doença-cuidado.

Em suma, Christopher Boorse levanta uma constelação de questões que concernem ao estatuto epistemológico necessário para a construção de uma ciência da saúde. Com impressionante honestidade intelectual, enfrenta algumas contraposições básicas - teoria $v s$. prática, normativismo vs. naturalismo, saúde $v s$. doença - que nos conduzem recursivamente a uma pergunta filosófica e epistemológica essencial: existirá um real, autônomo e independente, para além da linguagem, sempre captável pelo olhar do profissional de saúde e pelos aparatos das instituições reguladoras da doença? As críticas do presente texto de modo algum pretendem desacreditar a TBS como contribuição importante para os esforços empreendidos na compreensão da saúde, doença e conceitos correlatos. Muito pelo contrário. Apesar de todas as dissonâncias assinaladas, a obra boorseana logra compilar e articular problemas fundamentais para um debate que, direta ou indiretamente, interessa a todos os abrigados e interessados na construção do objeto deste campo que se designa como Saúde Coletiva. 


\section{Referências bibliográficas}

Almeida Filho N 2000a. Intersetorialidade, transdisciplinaridade e saúde coletiva: Atualizando um debate em aberto. Revista de Administração Pública 34(6): 11-34.

Boorse C 1975. On the distinction between disease and illness. Philosophy and Public Affairs 5:49-68.

Boorse C 1976a. What a theory of mental health should be. Journal of Theory Social Behaviour 6:61-84.

Boorse C 1976b. Wright on functions. Philosophical Review 85:70-86.

Boorse C 1977. Health as a theoretical concept. Philosophy of Science 44:542-573.

Boorse C 1987. Concepts of health, pp. 359-393.. In VanDeVeer D \& Regan T (eds.). Health care ethics: an introduction. Temple University Press, Filadélfia.

Boorse C 1997. A rebuttal on health, pp. 1-134. In Humber J \& Almeder R (eds.). What is disease? Human Press, Nova Jersey.

Brown WN 1985. On defining "disease”. Journal of Medical Philosophy 10:311-328.

Chaves M 1972. Saúde \& Sistemas. Editora FGV, Rio de Janeiro.

Engelhardt HT 1974. The disease of masturbation: values and the concept of disease. Bulletin of the History of Medicine 2(48):234-248.

Engelhardt HT 1976. Ideology and etiology. Journal of Medical Philosophy 1:256-268.

Engelhardt HT 1984. Clinical problems and the concept of disease, pp. 27-41. In Nordenfelt L \& Lindahl BIB (eds.). Health, disease and causal explanations in Medicine. Dordrecht, Reidel.

Engelhardt HT 1994. Closet logics: hidden conceptual elements in the DSM and ICD classifications of mental disorders, pp. 211-232. In Sadler J, Schwartz M, Wiggens $\mathrm{O}$ (eds.). Philosophical perspectives on psychiatric diagnostic classification. Johns Hopkins University Press, Baltimore.

Good B \& Good MJ 1980. The meaning of symptoms: a cultural hermeneutic model for clinical practice, pp. 165-196. In Eisenberg L \& Kleinman A (eds.). The relevance of social science for medicine. D. Reidel Publishing Co, Dordrecht, Holanda.
Good B 1994. Medicine, racionality, and experience. An anthropological perspective. Cambridge University Press, Nova York.

Hare RM 1986. Health. Journal of Medical Ethics 12:174181.

Kleinman A, Einsenber GL, \& Good B 1978. Culture, illness, and care. Clinical lessons from anthropologic and cross-cultural research. Annals of Internal Medicine 88 : 251-258.

Kleinman A 1986. Concepts and a model for the comparison of medical systems as cultural systems, pp. 2947. In Currer C, Stacey M (eds.). Concepts of health, illness and disease. A comparative perspective. Berg Publishers, Oxford.

Ladd J 1982, (Apud Boorse, 1997).

Lalande A 1995. Vocabulário Técnico e Crítico da Filosofia. Martins Fontes, São Paulo.

Nordenfelt L 1987. On the nature of health - an actiontheoretic approach. Kluwer Academic Publishers, Nova York.

Reznek L 1987. The nature of disease. Routledge and Kegan Paul, Londres.

Sackett DL et al. 1997. Evidence-based medicine: how to practice and teach EBM. Churchill-Livingstone, Londres.

Susser M 1973. Causal thinking in the health dciences. Oxford University Press, Nova York.

Wakefield JC 1992. The concept of mental disorder: on the boundary between biological facts and social values. American Pshychology 47:373-388.

Whitbeck C 1978. Four basic concepts of medical science, In Asquith PD \& Hacking (eds.). Philosophy of Science Association. MI: East Lansing.

Wulf HR, Pedersen SA \& Rosemberg R 1986. Phylosophy of medicine: an introducion. Blackwell Scientific Publications, Oxford, Reino Unido.

Young A 1982. The anthropologies of illness and sickness. Annual Review of Anthropology 11: 257-285.

Artigo apresentado em 27/8/2002

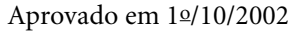

Versão final apresentada em 10/10/2002 